\title{
Estética e imaginário em Corda bamba de Lygia Bojunga Nunes.
}

\section{Daniela Yuri Uchino Santos ${ }^{1}$}

RESUMO: Com base nos estudos de Ítalo Calvino e de Jacqueline Held, pretendemos analisar a novela infanto-juvenil Corda bamba de Lygia Bojunga Nunes, no que diz respeito aos aspectos estéticos e ao imaginário da obra.

ABSTRACT: Based on studies of Ítalo Calvino and Jacqueline Held we intend to analyze the infantile-juvenile tale Corda bamba by Lygia Bojunga Nunes, in what it concerns to aesthetical aspects, and to the imaginary of the work.

PALAVRAS-CHAVE: Literatura para crianças e jovens, novela infanto-juvenil, Lygia Bojunga Nunes.

KEYWORDS: Literatures for children and youth, infantile-juvenile tale, Lygia Bojunga Nunes.

\section{Corda bamba - Estória}

O livro Corda $b a m b a^{2}$ de Lygia Bojunga Nunes é a narrativa de uma menina chamada Maria, de dez anos, que perde os pais, ambos equilibristas, em um acidente de trabalho no circo. Com isso, ela passa a viver na casa da avó materna. A convivência de Maria com a avó não é fácil, são personalidades distintas, adaptadas em ambientes outros. A autora, a partir daí, vai recompondo a infância de Maria, através do sonho, do imaginário, saindo do plano do real e entrando no maravilhoso; a narrativa transita entre essas duas dimensões. Maria sai da janela de seu quarto e começa a andar na corda bamba até o prédio vizinho, entrando pela janela deste, e defrontando-se com um corredor com portas coloridas. Em cada uma faz uma descoberta, um fato da vida de seus pais, de sua avó e de sua própria vida. Na última porta Maria recorda como aconteceu o acidente que vitimou

1 Mestranda em Estudos Comparados de Literaturas de Língua Portuguesa, FFLCH-USP. Pesquisa: Traços de modernidade nas obras de Lygia Bojunga Nunes e Alice Vieira. E-mail: daniela.yuri1@itelefonica.com.br. ${ }^{2}$ BOJUNGA, Lygia. Corda Bamba. Rio de Janeiro, Casa Lygia Bojunga, 2003. 
fatalmente seus pais. E no final da narrativa, ela passa a pensar em um futuro com escolhas próprias, continuando a eterna busca pela identidade.

\section{Estética literária em Corda Bamba}

Lygia Bojunga se aventura pelas veredas da imaginação infanto-juvenil e arma sobre o jovem e respeitável público a lona de seu circo de surpresas e encantamento, apresentando-lhe esta CORDA BAMBA, através da qual Maria, filha de equilibristas, e também ela artista de circo, resolve viajar para dentro de si mesma. Viver na corda bamba - é como o imaginário popular define a existência de quem tem que enfrentar desafios diários para sobreviver. Assim caminha Maria em busca de seu próprio equilíbrio, abrindo as portas do passado e recompondo-se dos dramas que marcaram sua infância circence. 3

Da citação acima, interessa-nos primeiramente ressaltar o equilíbrio. Equilíbrio da narrativa no sentido da construção da estória, através da linguagem. E a seguir o equilíbrio da personagem na "corda bamba" da vida, enfrentando problemas, e resgatando a si mesma através do imaginário.

Para refletir a esse respeito, consideramos útil recordar as conferências preparadas por Ítalo Calvino para a Universidade de Harvard, nunca proferidas devido à morte súbita do autor, mas postumamente publicadas no livro Seis propostas para o próximo milênio 4 . Para Calvino5: “(...) Há coisas que só a literatura com seus meios específicos nos pode dar”: Leveza, Rapidez, Exatidão, Visibilidade, Multiplicidade, são os temas das suas cinco conferências. Consistência era o tema da última conferência que jamais foi escrita.

Para Calvino, em linhas gerais, um objeto artístico literário possui: Leveza: uma linguagem sem peso, sutil, mas ao mesmo tempo associada à precisão e à determinação. Rapidez: a economia da narrativa, o segredo do ritmo. Exatidão: imagens visuais nítidas e memoráveis, uma obra bem definida, uma linguagem precisa e que seja capaz de traduzir as nuances do pensamento. Visibilidade: transparência do pensamento, do imaginário individual do artista. Multiplicidade: conexões entre fatos, pessoas, entre coisas do mundo.

\footnotetext{
${ }^{3}$ BOJUNGA, Lygia. Idem, ibidem, contra-capa.

${ }^{4}$ CALVINO, Ítalo. Seis propostas para o próximo milênio. São Paulo, Companhia das letras, 2001.

${ }^{5}$ CALVINO, Ítalo. Idem ibidem, p. 11.
} 
Em toda a narrativa de Corda Bamba podemos encontrar as questões levantadas por Calvino. A leveza a que Calvino se refere pode ser encontrada na linguagem, que é sutil, precisa, sem excessos. As palavras não trazem peso, trazem leveza. Elas fluem no texto de forma exata e funcional. Por isso a leveza está associada a rapidez e a exatidão, multiplicidade e visibilidade, pois uma boa narrativa sabe condensar todas essas nuances. A rapidez está presente na obra através do ritmo do texto. Ora a narrativa está nos diálogos, ora nos pensamentos de Maria, ora nas personagens que vão nos ajudando a conhecer a estória. Ao mesmo tempo que a narrativa é rápida, o texto flui sem tropeços, porque é um texto de narrativa leve. Há uma ligação entre todas as propostas como já foi dito acima. $\mathrm{E}$ sobre leveza da linguagem, diz Calvino:

Neste ponto devemos recordar que se a idéia de um mundo constituído de átomos sem peso nos impressiona é porque temos experiência do peso das coisas; assim como não podemos admirar a leveza da linguagem se não soubermos admirar igualmente a linguagem dotada de peso. ${ }^{6}$

O autor faz um contraponto entre peso e leveza das coisas e da linguagem e por sabermos a diferenciação delas através da experiência é que reafirmamos a leveza de linguagem na narrativa de Lygia Bojunga, caracterizada na forma dos períodos, na pontuação, no léxico, construindo o texto e expondo para os leitores personagens e idéias. E retomando a rapidez, o tempo e o ritmo da narrativa, citando o exemplo das Mil e uma noites, diz Calvino:

A arte que permite a Sheherazade salvar sua vida a cada noite está no saber encadear uma história a outra, interrompendo-a no momento exato: duas operações sobre a continuidade e a descontinuidade do tempo. É um segredo de ritmo, uma forma de capturar o tempo que podemos reconhecer desde as suas origens: na poesia épica por causa da métrica do verso, na narração em prosa pelas diversas maneiras de manter aceso o desejo de se ouvir o resto. ${ }^{7}$

Sobre o "segredo do ritmo" de Corda bamba, podemos dizer que é esse fluir da narrativa dos pensamentos de Maria para os diálogos e para outras personagens, do real

\footnotetext{
${ }^{6}$ CALVINO, Ítalo. Idem, ibidem, p. 27

${ }^{7}$ CALVINO, Ítalo. Idem, ibidem, p. 51.
} 
para o imaginário e do recuo do tempo presente para o passado, através da sistemática troca de portas, que pode até estabelecer um paralelo com as sistemáticas seqüências de estórias de Sheherazade. Corda bamba é uma narrativa que explora os meandros da consciência da criança, e sob o seu foco são vistos os acontecimentos de sua vida no passado, e no presente. Do ponto de vista da menina Maria com dez anos, com sua sensibilidade e percepção aguda dos fatos, a estória trata a dor da perda dos pais, a dor do abandono, a ruptura de um modo de vida, o choque de valores entre a educação que recebeu dos pais, e depois sob a guarda da avó, a incompreensão dos problemas da criança - o adulto sobrepujando suas vontades, mostrando o seu poder em relação à criança, como no capítulo “Aula Particular" em que é explorado esse aspecto na relação entre a professora particular e Maria. Trata também da solidão que leva a criança a construir um mundo só seu, por meio do imaginário, como um salvo-conduto, para enfrentar a realidade da vida, e no caso de Maria para se reconstruir reconstruindo seu passado. Ela fica conhecendo o início do romance de seus pais, a vida que levavam, a batalha pela sobrevivência que empreenderam juntos do começo ao fim, sem depender financeiramente da avó. É o começo da estória de sua vida, como um resgate da memória, para poder entender os pais, a avó, a si mesma e a realidade presente. $\mathrm{O}$ mundo particular da criança é explorado em toda a sua potencialidade nessa obra, pois Maria é salva pelo imaginário. Para a superação da perda, da morte dos pais, e para um caminho de escolhas no futuro. A narrativa aponta aos leitores, crianças ou não, que há perdas irreparáveis em uma vida, mas há um futuro, na ficção/na realidade que direciona para as escolhas, para as "Portas novas" da narrativa. "Portas novas" é o título do capítulo que encerra o romance e pode ser uma síntese para falar da exatidão na obra. Os títulos representam com precisão o assunto a ser tratado nos capítulos, e concentram no verbal o foco temático destes. A narrativa capta os pensamentos das personagens, o imaginário da criança de forma exata, precisa, sem excessos, com imagens visuais nítidas. A linguagem traduz as nuances do pensamento de Maria, de forma direta, mas ao mesmo tempo leve, sutil, delicada e intensa. Calvino apresenta três itens a respeito de exatidão numa obra literária: "1) Um projeto de obra bem definido e calculado; 2) A evocação de imagens visuais nítidas, incisivas, memoráveis; 3) Uma linguagem que seja a mais precisa 
possível como léxico e em sua capacidade de traduzir as nuanças do pensamento e da imaginação". 8

Corda bamba com uma linguagem, por vezes, cinematográfica, percebida na acuidade visual das cenas que constituem o desenrolar da narrativa e o encadeamento das seqüências do pensamento, desde as coisas triviais da vida cotidiana para o imaginário, emprega continuamente a oralidade do discurso narrativo: eis a exatidão na obra.

A boa construção das personagens pela autora, com suas problemáticas encadeadas no corpo da narrativa traduz a sua visibilidade de pensamento. Percebemos a clareza nos pensamentos de Maria, a transparência do imaginário da autora, ganhando forma, com uma linguagem precisa. Um texto exato, sutil e ritmado é capaz de nos mostrar a transparência do pensamento do artista. Sobre os processos imaginativos, Calvino nos diz:

Podemos distinguir dois tipos de processos imaginativos: o que parte da palavra para chegar à imagem visiva e o que parte da imagem visiva para chegar à expressão verbal. O primeiro processo é o que ocorre normalmente na leitura: lemos por exemplo uma cena de romance ou a reportagem de um acontecimento num jornal, e conforme a maior ou menor eficácia do texto somos levados a ver a cena como se esta se desenrolasse diante de nossos olhos, se não toda a cena, pelo menos fragmentos e detalhes que emergem do indistinto. ${ }^{9}$

Nos dois planos narrativos em Corda bamba, o real e o imaginário de Maria, nos defrontamos com classes sociais diferentes, percebemos relações familiares, sociais, econômicas e políticas, cada qual com interesses diversos, permeando toda a narrativa com ambientes, pessoas e personalidades outras. Logo, há multiplicidade. Coexistem várias dimensões dentro do romance, tanto por parte de Maria, de seus pensamentos, e de seu imaginário, em que há distinções de tempo bem definidas quanto com relação às descobertas do passado, a vida no presente e as coisas práticas do dia-a-dia. $\mathrm{O}$ imaginário de Maria interage com a vida real. Ela transita pelo passado, presente e resvala no futuro. A autora passa de um plano a outro, real e imaginário, sem explicações, sem didatismos. No plano da ficção, as noções de tempo e espaço ganham novas dimensões. Estas só podem ser reveladas por um olhar de descoberta, nascido das infinitas possibilidades de leitura que

\footnotetext{
${ }^{8}$ CALVINO, Ítalo. Idem, ibidem, p.71.

${ }^{9}$ CALVINO, Ítalo. Idem, ibidem, p.99.
} 
esta obra literária e a própria literatura possibilitam. Calvino diz que o universo da literatura é diferente do universo do viver, uma vez que a literatura nos permite outras formas de abordagem, outra ótica, diversos ângulos, vários pontos de observação desse mesmo viver. Nas palavras de Calvino: "Apenas a vivacidade e a mobilidade da inteligência escapam à condenação - qualidades de que se compõe o romance e que pertencem a um universo que não é mais aquele do viver". ${ }^{10}$

E ainda, sobre multiplicidade, o último tema das cinco conferências, nos diz Calvino:

O conhecimento como multiplicidade é um fio que ata as obras maiores, tanto do que se vem chamando de modernismo quanto do que se vem chamando de pósmodernismo, um fio que para além de todos os rótulos - gostaria de ver desenrolando-se ao longo do próximo milênio. ${ }^{11}$

Podemos perceber em Corda bamba todos esses processos com relação à diversidade e as conexões entre fatos, pessoas e coisas do mundo.

A sexta proposta de Calvino não foi escrita. Seu tema era Consistência. Palavra essa que significa firmeza, densidade, coerência. Portanto falar em consistência na literatura poderia ser falar no sentido totalitário da obra, numa obra literária sólida, perfeita, uma obra-prima, provavelmente nascida de um "descontentamento com o mundo" e onde se conjuga a "felicidade da expressão verbal" nos dizeres de Calvino na citação acima. Mas ao mesmo tempo, num texto consistente há leveza, rapidez, visibilidade, exatidão e multiplicidade. Consistência, poderia ser o resultado da união de todas as outras cinco propostas.

Corda Bamba é um texto consistente no qual as propostas de Calvino coexistem dentro da obra, equilibram-se na construção da narrativa, resultando numa obra densa, com uma problemática ampla, vista em imagens narrativas perfeitas.

\footnotetext{
${ }^{10}$ CALVINO, Ítalo. Idem,ibidem, p. 19.

${ }^{11}$ CALVINO, Ítalo. Idem, ibidem , p.58-130.
} 


\section{O Imaginário em Corda Bamba}

Jacqueline Held em seu livro $O$ Imaginário no poder $^{12}$ defende a questão do imaginário, no sentido de que ele abre novas possibilidades de ser para a criança. E nas primeiras páginas, com uma linguagem direta, taxativa, ela diz:

Digamos, desde já, e claramente: o imaginário de que nos ocuparemos não é esse pseudo-imaginário com função de esquecimento, de exorcismo e de diversão, que desvia a criança dos verdadeiros problemas, do mundo de hoje e de amanhã. ${ }^{13}$

O que a autora propõe é uma leitura do real que passa pelo imaginário, e não o imaginário como um fator de alienação do real. O imaginário visto como um meio de revelação do real. Podemos até dizer que seu emprego é um método funcional dentro de uma narrativa, quando bem empregado, usado sem didatismos.

Corda Bamba, como já foi dito, é uma obra que explora o imaginário em toda a sua potencialidade, pois através dele, a personagem Maria reconstitui e reconstrói a sua vida, começando pelo romance de seus pais. $\mathrm{O}$ imaginário nessa novela juvenil não é um mero adereço, pois exerce uma funcionalidade, o conhecimento, o entendimento dos fatos e da maneira de ser das pessoas, para que assim Maria possa reconhecer a si mesma. Na verdade a personagem percorre os meandros do imaginário que transfere, integra e flui para o real na busca de sua identidade. Temos Maria com seus apenas dez anos de história de vida respeitando-se a criança como um ser humano completo e não como um vir a ser, ou seja, que a criança tem conhecimento de mundo, no limite de sua idade. Assim, podemos dizer que Corda Bamba é uma novela juvenil que trabalha com a memória resgatada pelo imaginário para reconstruir e reatar o fio bipartido da vida da personagem, a ruptura, a cisão causada pela tragédia da perda dos pais.

E continuando com os conceitos de Held: "A ficção se assemelha a um brinquedo. A ficção não deveria abrir todas as espécies de portas, permitir à criança imaginar outras possibilidades de ser para que possa, finalmente, escolher-se?" 14

\footnotetext{
${ }^{12}$ HELD, Jacqueline. O Imaginário no poder. São Paulo, Summus Editorial, 1980.

${ }^{13}$ HELD, Jacqueline. Idem, ibidem, p. 22.

${ }^{14}$ HELD, Jacqueline. Idem, ibidem, p.17.
} 
Para usar o termo ao qual já nos referimos, abrir "portas". Portas literalmente abertas por Maria no imaginário, cada uma sendo uma revelação do real. Real que vai se juntando a outros fatos, sendo costurado, reconstituindo-se o fio bipartido da vida da personagem. Reconstrução esta que possibilita à personagem no final da narrativa, vislumbrar um futuro com escolhas próprias. Possibilidade dada pela maestria da autora ao explorar o imaginário, comprometendo-se com a literatura como arte.

Maria uma menina tímida que, após a perda dos pais, tem de conviver em um novo ambiente e com uma avó que não lhe dá afeto, nem compreensão. Lembremos aqui a aula da professora particular, cujo cachorro permanece todo o tempo embaixo da mesa, junto de Maria e causando-lhe medo, mas a professora não dá ouvidos para o problema, e tampouco a avó.

E sobre isso, nos diz Held:

A criança, pois, seus próprios problemas, importantes para ela, mesmo quando nos parecem fúteis, muitas vezes erroneamente. Levando-se em conta a importância, ao menos quantitativa, que a escola tem na vida infantil, não é de surpreender que a atmosfera que aí se instala, as dificuldades a vencer, as rivalidades que se originam, as relações que se estabelecem seja entre diferentes escolares, seja entre alunos e professores, estejam no centro das preocupações infantis. ${ }^{15}$

Em O Imaginário no poder, Jacqueline Held abre uma discussão sobre os efeitos da produção dirigida à criança. Discorre sobre a fantasia na literatura infantil, e mais ainda, aborda uma forma de percepção da criança em sua relação com o mundo.

Sobre essa questão, podemos dizer que Corda Bamba é uma obra para ser lida por um leitor fluente, e sendo uma novela infanto-juvenil, pode começar atendendo a esse público. O ponto de vista, a ótica e a percepção aguçada de Maria vão desde o início contando a estória através das cenas, dos fatos; e a relação da personagem com o mundo, com as pessoas, são indícios de seu mundo particular e da preparação para o mergulho no imaginário que faz a autora, sem medo, sobretudo do tema que trata, a morte dos pais para uma criança de dez anos, acostumada a viver em um outro ambiente. O sentimento de cada leitor desta narrativa que passou ou não por essa tragédia em sua vida é singular e único,

\footnotetext{
${ }^{15}$ HELD, Jacqueline. Idem,ibidem, p.131.
} 
pois partindo-se do imaginário da ficção é possível fazer uma analogia com as experiências vividas por cada indivíduo em sua história de vida. Não é justo e nem verdadeiro com a criança que lhe dêem apenas o "livrinho feliz", pois a criança tem o direito de experimentar e saborear a leitura para poder fazer suas escolhas pessoais e livres de pré-conceitos estabelecidos e arraigados por toda e qualquer sociedade.

Para Maria, frente a sua realidade trágica, restou o imaginário, o "sonho, motor constante do real". ${ }^{16}$ Sobre essas e outras questões, continuamos com Held:

Último "poder", essencial mas que poderíamos crer exclusivamente adulto, o poder exercido sobre o coração do outro. Não poderia, certamente, possuir forma idêntica nas diferentes idades da vida. No entanto, se considerarmos o amor durável como muralha contra a solidão, se eliminarmos a dimensão erótica e carnal especificamente adulta para acentuar o que a vida afetiva de uma criança já permite experimentar, viver, desejar, uma amizade predileta, uma presença, um diálogo que jamais lhe faltem, a ternura de um pai ou de uma mãe, então sim, sem nenhuma dúvida, a criança aspiraria ao poder de se garantir com o amor durável. ${ }^{17}$

Maria perdeu seu "amor durável”, a atenção, o carinho e afeto do pai e da mãe. Podemos falar do poder do imaginário. O poder do imaginário de Maria que recorrendo e resgatando um símbolo de seu agrado, estima e valor "o arco, a corda" vai equilibrando-se na "corda bamba" da vida, enfrentando problemas, abrindo as portas do passado, viajando para dentro de si mesma através do imaginário. Para essa travessia, houve um período de muita introspecção, próprio da personalidade tímida de Maria, que nem por isso a torna frágil. Talvez seu exterior, seus gestos delicados, seus silêncios, dêem a impressão de fragilidade. Ela é densa, profunda e forte, tendo conseguido enfrentar seus problemas no dia-a-dia. E a cada passo, a cada porta aberta uma descoberta ou rememoração. Essa caminhada envolve muitos silêncios, muitas frases não ditas em lugar dos monossílabos e dos muitos pensamentos turbilhonando as emoções e os sentimentos na solidão do quarto, da janela. A visão da janela, pela personagem, o silêncio e os pensamentos na solidão caminham juntos com as dores, dentro do mundo particular de Maria. Quietude e reflexão podendo ser percebidas delicadamente através da linguagem leve e precisa e da cena de Maria na janela no segundo capítulo da narrativa intitulado Janelas.

\footnotetext{
${ }^{16}$ HELD, Jacqueline. Idem, ibidem, p. 169.

${ }^{17}$ HELD, Jacqueline. Idem, ibidem, p.138.
} 
Enfim, Maria com sua timidez, instrospecção, e sensibilidade, foi salva por si mesma através do imaginário, e a narrativa termina abrindo-se com as "Portas novas", com as escolhas para o futuro que a ela pertencem, recriando e construindo a sua vida, mesmo com a infância marcada pela tragédia.

\section{Referências bibliográficas}

BOJUNGA, Lygia. Corda bamba. Rio de Janeiro, Casa Lygia Bojunga, 2003.

CALVINO, Ítalo. Seis propostas para o próximo milênio. Trad. Ivo Barroso. São Paulo, Companhia das letras, 1990.

HELD, Jacqueline. O imaginário no poder. Trad. Carlos Rizzi. São Paulo, Summus Editorial, 1980. 